\title{
Memorial to Prof. Paolo Bono 1940-2012
}

\author{
James W. LaMoreaux $\cdot$ Marco Petitta • \\ Giuseppe Capelli · Hai Thanh Tran
}

Published online: 13 August 2013

(c) Springer-Verlag Berlin Heidelberg 2013

Professor Paolo Bono passed away in February, 2012 before he was able to see this special issue of Environmental Earth Sciences come to fruition. He was integrally involved in planning and implementing the Geokarst Hazards Conference due to his long-term interest in and investment in the karst of Vietnam. Paolo will be missed and there follows a memorial to him prepared by his colleagues at the University of Rome "La Sapienza" and Professor Hai Tran, organizer of the conference.

Paolo was born in Kalimnos, Greece, March 15, 1940. $\mathrm{He}$ served as an Associate Professor of Hydrogeology beginning in the 1980s at the University of Rome "La Sapienza", teaching students of Geological Sciences and Environmental Sciences. He retired at the end of 2010. Since the 1970s his researches were related to Regional Quantitative Hydrogeology in regards to resource occurrence, hydrostructure boundary conditions and assessment of renewable groundwater resources in Italy. At the same time he was active in national and international multidisciplinary projects promoted by the National Research

J. W. LaMoreaux

P.E. LaMoreaux \& Associates, Inc., Tuscaloosa, AL, USA

M. Petitta $(\bowtie)$

Dipartimento di Scienze Della Terra, Universita' di Roma La

Sapienza, Rome, Italy

e-mail: marco.petitta@uniroma1.it

G. Capelli

Dipartimento di Scienze Geologiche, Universita' Roma Tre, Rome, Italy

e-mail: capelli@uniroma3.it

\section{H. T. Tran}

Geology Department, Hanoi University of Mining and Geology,

Dong Ngac, Tu Liem, Hanoi, Vietnam

e-mail: tranthanhhai.humg@gmail.com
Council (CNR). In the 1980s he performed hydrological and hydrogeological investigations and taught training courses within the framework of a cooperative program between the governments of Italy and Lesotho. Since the 1990s he devoted his research to environmental pollution, with particular reference to hydrochemistry and water isotope data ranging from rain to spring water. During the last 10 years, he was involved in international projects for the evaluation of groundwater resources in the Galapagos Islands, Socotra Island and in Vietnam, under the umbrella of the Italian Ministry of Foreign Affairs and of UNESCO. Paolo was a member of the Scientific Council of the "Research Center for Quaternary and Environmental Evolution" of the CNR, of the Karst Commission of the International Association of Hydrogeologists (IAH) and of the Scientific Committee of CISDAM (Interdisciplinary Center of Studies on Mediterranean Environments). He served for many years on the Editorial Board of Geologica Romana, Journal of the Earth Science Department of La Sapienza University, and, of course, on the Editorial Board of Environmental Earth Sciences (formerly Environmental Geology).

Results of his research activity have been published in national and international journals, conference proceedings and official reports. Particular recognition is due to the highquality hydrogeological maps he contributed to the field, including the Hydrogeological Scheme of Central Italy, 1986. Today this is still the basic hydrogeological map used in Central Italy for scientific and technical purposes.

In addition to the above biographical sketch, which briefly and incompletely describes the official activity of the scientist, we want to add our modest description of the man, colleague and researcher, that Paolo was during his long tenure at La Sapienza University.

Paolo was a strong, tenacious, tireless man, who dedicated his life to hydrogeology, through research and 
teaching. First of all, he had a strong character and he also had a great heart dedicated to people in developing countries less fortunate than those in more developed countries. Having spent decades of research life in close proximity to and parallel to that of Paolo, it was impossible not to absorb his enthusiasm for geological topics and to place experimental and quantitative hydrogeology as a priority before all others. Among the academic community, Paolo has been duly recognized for his unique experimental approach, even under extreme consequences; measuring all that is measurable, frequently and for long duration even for several years, if possible. Unfortunately, this approach, because of the enormous amount of data collected, creates difficulty to find sufficient time for elaborating upon and synthesizing data and models to be published. The particular way in which he performed his research allowed him to realize hydrogeological studies of great interest, both on a regional scale (Central Italy, Volsci Mts., Lesotho) and a local scale (Acque Albule Basin, karst spring of Inferniglio, Aniene River Basin). During the last 15 years of teaching environmental science students, he demonstrated sensitivity to multidisciplinary approaches and to environmental themes, anticipating the tendency of hydrogeology to merge with environmental sciences.

One of his major, and most evident characteristics, was his strong charisma, which immediately transmitted enthusiasm to younger people, either as undergraduates, post graduate fellows, PhD's or others. Inevitably, Paolo's research approach and attitude have significantly influenced the atmosphere and attitude of the research groups he coordinated. Many colleagues and friends have expressed their high regards and commented on Paolo's memorable attitude.

A couple of anecdotes can better explain his attitude.

G. Capelli shared the adventure that he experienced with Paolo during the 1970s and 1980s, in the development of new research projects on "experimental and representative hydrographic basins" and on "coastal lakes in Latina Province", where Paolo lived with his family. He managed a network of tens of climatic and hydrological monitoring stations, for both surface and groundwater. In the implementation of these stations, generations of students worked with the academic staff. Several men-at-work sites became active in building monitoring stations. To install hydrometrographs, cubic meters of concrete were required, with locally built iron structures, along with river bed adjustments in the gauging stations, and an enormous quantity of technical and scientific instruments. Where vans were not able to reach the sites, mules were used for transporting the materials. Paolo was officially the technical site manager, while the students and I acted as handymen. At the end of this phase, the work to calibrate and manage the stations was only beginning. Measurements of stream discharge to define correlation between discharge and water level was one of the most challenging activities requiring night and day surveys, during hot and cold periods. Paolo convinced us of this priority; he was able to obtain the commitment of all people, with the voice and gestures of a scientific man. During the Coastal Lake project, about ten contract researchers worked for years on the hydrogeology, hydrology and hydrochemistry. They followed difficult schedules, frequently all night long, to stay on a timetable so intense and hard that only Paolo could imagine and realize! Nevertheless, like the polar explorer Shackleton in his famous advertisement in 1914, he was looking for men for a dangerous venture, offering low income, cold climates, and perhaps the glory and doubt about the return trip. Paolo was able to excite in his collaborators the ideals to stimulate them to offer the best they could for the progress of science. Unfortunately and in contrast to the English explorer, Paolo frequently lost his men, because in comparison with the huge experimental phase, the scientific synthesis was slower and not in accord with actual requirements of publication frequency.

M. Petitta remembers that at the end of the 1980s, after completing his degree, he found a "chair" in Paolo's Lab, at the time the first Macintosh was bought and utilized to archive data and produce graphs. Paolo suddenly discovered the possibility to synthesize the large amount of data he had collected in the previous 25 years. As a consequence, I was inundated by plots, schemes and numbers which until that time were archived by Paolo in simple drawings (see below). In fact, and perhaps because of his technical studies in college, or more probably because of his artistic nature, it was his habit to prepare sketches to explain the hydrogeological problem to be solved. His drawings were perfect "conceptual models" of the groundwater flow and hydrologic cycle, in different contexts!

With Carlo Boni and Gian Maria Zuppi, both having passed away in the last 5 years, Paolo was on the front line for the introduction in Italy of the analytical method of water isotopes, a fundamental factor in defining the hydrogeological scheme and identifying the recharge area of the large aquifers of Central Italy. The scientific dialectic forced us in several cases to be on different sides, with the duty to find models and scenarios of knowledge, looking to offer the best solution to land and water administrators.

Taking into account the long professional tenure spent at his side, we can affirm that Paolo continues to represent a basic reference point for the international hydrogeological community, a researcher and a teacher, valid and tireless, who interpreted with coherence and discipline the spirit of his mission. Personally, he was first a guide and subsequently a fellow traveler; sharing a way of study and of life with him was not easy all the time.

Ciao Paolo, we will always be bound by the same intent. 


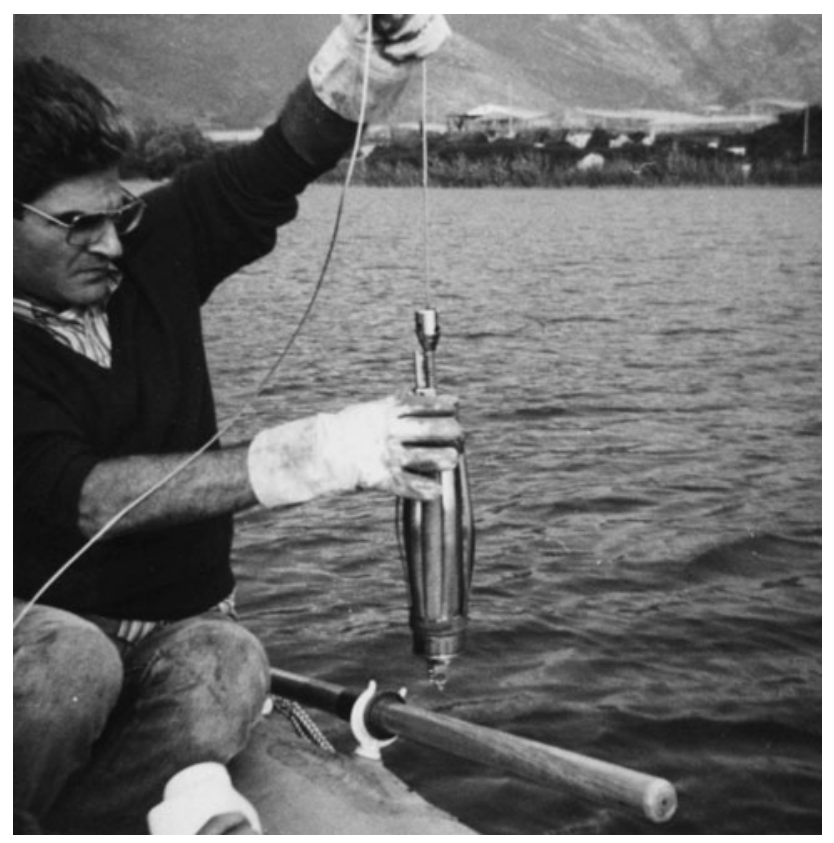

Paolo Bono during his preferred activity: sampling and monitoring

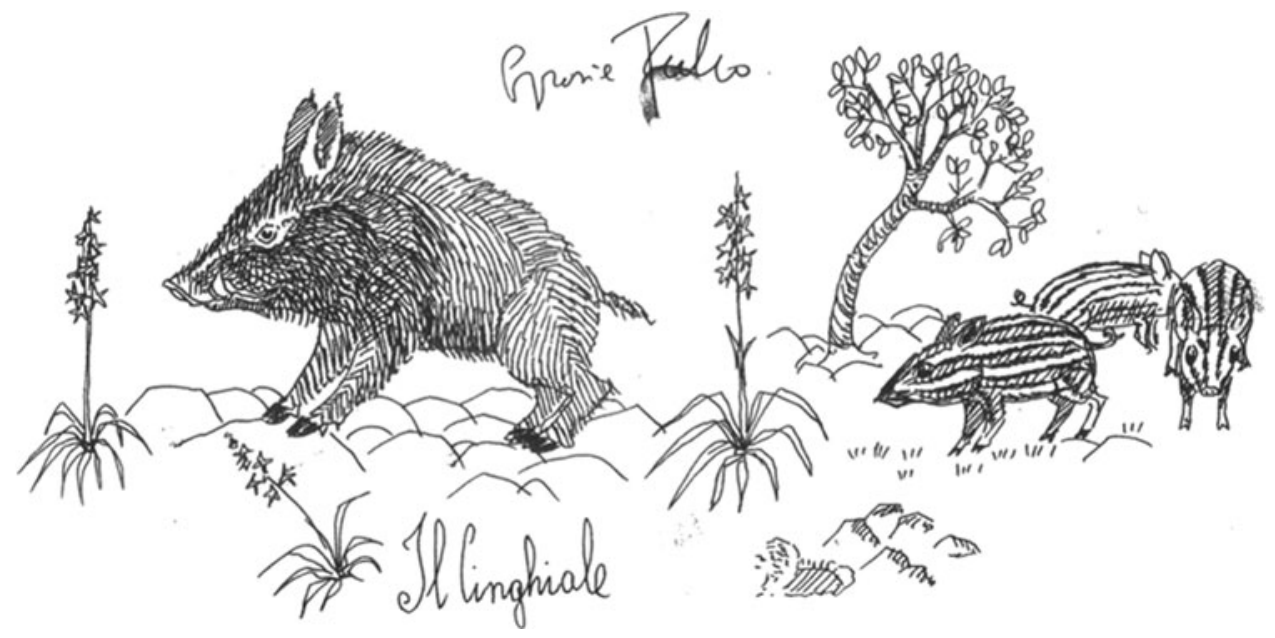

A drawing of Paolo Bono 